\title{
Retinoic acid induces white adipose tissue browning by increasing adipose vascularity and inducing beige adipogenesis of PDGFR $\alpha^{+}$adipose progenitors
}

\author{
Bo Wang ${ }^{1,2}$, Xing Fu ${ }^{1}$, Xingwei Liang ${ }^{1}$, Jeanene M Deavila ${ }^{1}$, Zhixiu Wang ${ }^{1}$, Liang Zhao ${ }^{1}$, Qiyu Tian ${ }^{1}$, \\ Junxing Zhao ${ }^{3}$, Noe Alberto Gomez ${ }^{1}$, Sophie C Trombetta ${ }^{1}$, Mei-Jun Zhu ${ }^{4}$, Min $\mathrm{Du}^{1,2, *}$ \\ ${ }^{I}$ Nutrigenomics and Growth Biology Laboratory, Department of Animal Sciences, Washington State University, Pullman, WA, \\ USA; ${ }^{2}$ Advanced Innovation Center for Food Nutrition and Human Health, China Agricultural University, Beijing, China; \\ ${ }^{3}$ College of Animal Science and Veterinary Medicine, Shanxi Agricultural University, Taigu, Shanxi, China; ${ }^{4}$ School of Food \\ Sciences, Washington State University, Pullman, WA, USA
}

Formation of beige adipocytes within white adipose tissue enhances energy expenditure, which is a promising strategy to reduce obesity and prevent metabolic symptoms. Vitamin A and its bioactive metabolite, retinoic acid (RA), have regulatory roles in lipid metabolism. Here we report that RA induces white adipose tissue browning via activating vascular endothelial growth factor (VEGF) signaling. RA triggered angiogenesis and elicited de novo generation of platelet-derived growth factor receptor $\alpha$ positive (PDGFR $\alpha^{+}$) adipose precursor cells via VEGFA/VEGFR2 signaling. In addition, RA promoted beige/brown adipocyte formation from capillary networks in vitro. Using PDGFR $\alpha$ tracking mice, we found that the vascular system acted as an adipogenic repository by containing PDGFR $\alpha^{+}$progenitors which differentiated into beige adipocytes under RA or VEGF164 treatments. Conditional knockout of VEGF receptors blocked RA-stimulated white adipose tissue browning. Moreover, the VEGFA and RA activated p38MAPK to enhance the binding of RA receptor to RA response elements of the Prdm16 promoter and upregulated Prdm16 transcription. In conclusion, RA induces white adipose tissue browning by increasing adipose vascularity and promoting beige adipogenesis of PDGFR $\alpha^{+}$adipose progenitors.

Keywords: adipose progenitor; angiogenesis; beige adipogenesis; retinoic acid; vitamin A; VEGF

Cell Discovery (2017) 3, 17036; doi:10.1038/celldisc.2017.36; published online 10 October 2017

\section{Introduction}

Due to the global obesity epidemic, there is an urgency for an increased understanding of adipose tissue development and its roles in metabolic dysfunction. While adipocytes are benign and functional at regular sizes, adipocyte hypertrophy can lead to tissue hypoxia [1] and interstitial fibrosis [2], which results in adipose metabolic dysfunction [3]. The formation of brown adipocytes within white adipose tissue (WAT), termed beige adipogenesis, enhances energy expenditure and provides a new alternative for preventing and reducing obesity and other metabolic symptoms [4].

*Correspondence: $\mathrm{Min} \mathrm{Du}$

Tel: +509 335 2744; Fax: +307 766 2355;

E-mail:min.du@wsu.edu

Received 28 April 2017; accepted 31 August 2017
However, contemporary knowledge about the origins of beige adipocytes and mechanisms regulating beige adipogenesis remains rudimentary.

The process of adipogenesis is spatially and temporally associated with vascular development, therefore, high vascularization is observed in mature adipose tissue [5]. The function of this vascularization is not simply limited to providing oxygen and nutrients, but also transporting metabolic products such as transporting growth factors [6] which are critical for adipose tissue expansion and remodeling [7]. Consistently, adipose-derived stem cells of diabetic mice have lower angiogenic potential [8]. It has also been shown that the angiogenic capacity of subcutaneous adipose tissue decreases with morbid obesity [9]. Deletion of vascular endothelial growth factor a $(V e g f a)$, a growth factor critical for angiogenesis, reduces vascular density and leads to adipose hypoxia, apoptosis, inflammation and 


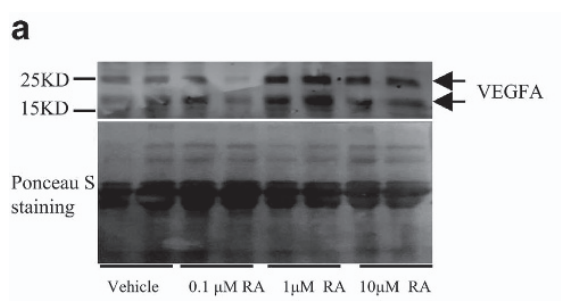

d

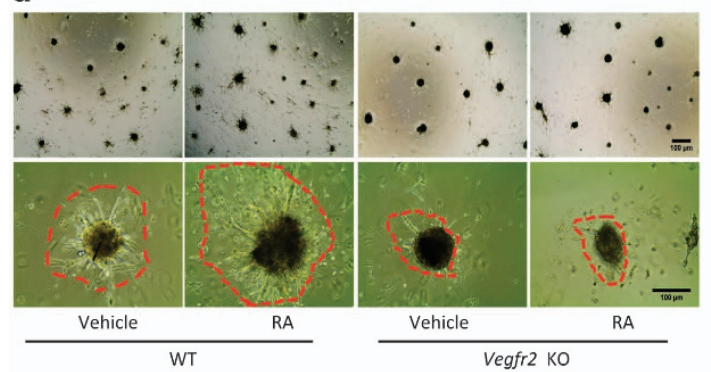

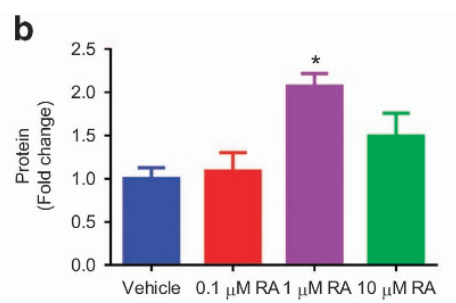

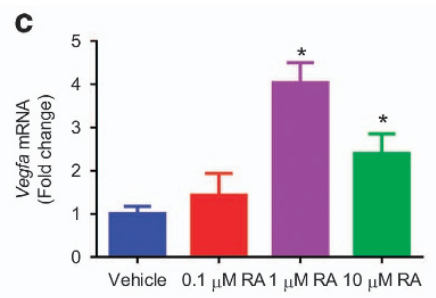

$\mathbf{f}$
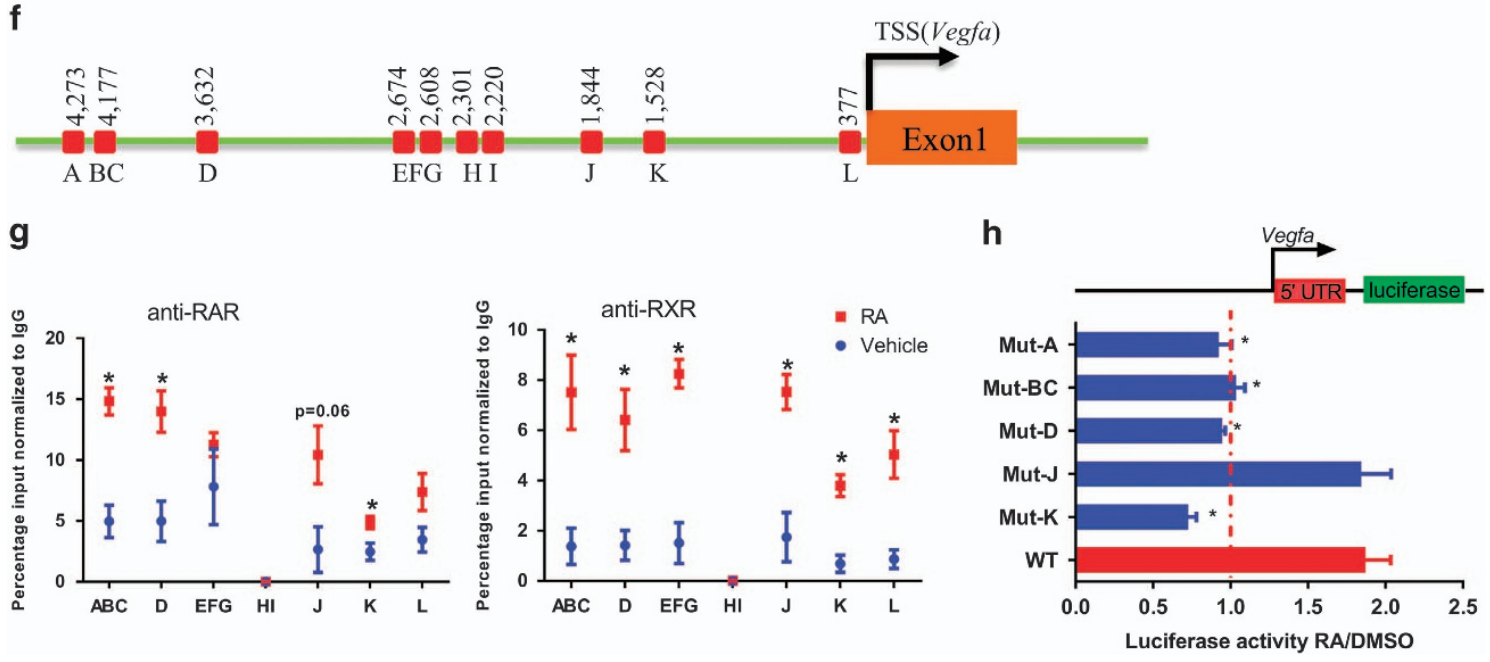

Figure 1 RA promotes in vitro angiogenesis of SVCs via VEGFA/VEGFR2 signaling. (a) VEGFA protein content in the medium cultured with adipose-derived SVCs for 2 days, and cells were treated with different doses of RA. (b) Quantification of VEGFA protein, data presented were normalized according to the content of a non-specific band. (c) The expression of Vegfa in SVCs treated with RA for 2 days. (d) Representative images (scale bar $=100 \mu \mathrm{m}$ ), and (e) Vegfa expression of adipose tissue derived control or Vegfr2 knockout SVCs cultured on matrigel-coated plates in endothelial basal medium for 2 days with or without $1 \mu \mathrm{M}$ RA (same doses for other in vitro studies if unstated). (f) Putative retinoic acid response elements (pRARE) on the Vegfa promoter are indicated by letters, some of which share several nucleotides; closely located pRARE were analyzed using one pair of primers. (g) SVCs were treated with RA or DMSO for $4 \mathrm{~h}$, and binding of RAR and retinoid X receptor (RXR) to pRAREs were analyzed by ChIP. (h) The pRARE sites with altered RAR/RXR binding due to RA were chosen. These sites on a Vegfa promoter luciferase reporter plasmid were mutated. The luciferase activity of WT and mutated Vegfa promoter reporter plasmids were analyzed after $4 \mathrm{~h}$ of RA treatment. Data presented are mean \pm s.e.m., $n=6,{ }^{*} P<0.05$.

metabolic defects on a high-fat diet [10]. In contrast, Vegfa overexpressing increases adipose vasculature and improves insulin sensitivity $[10,11]$. It was recently discovered that adipose-specific Vegfa overexpression induced WAT browning, which increases energy expenditure [12]. Given that pericytes and endothelial cells can differentiate into adipocytes [13, 14], blood vessels may act as a progenitor pool for adipocyte replenishment [6]. On the other hand, in a threedimensional culture environment, preadipocytes have the potential to induce endothelial cell migration [15]. Thus, endothelial cells and adipocytes interplay through reciprocal exchange of growth factors, hormones and cytokines [5].

Retinoic acid (RA), a metabolite of vitamin A, is an important regulator of lipid metabolism [16]. Ablation 
of retinol dehydrogenase $1(r d h l)$, an enzyme that produces the precursors of RA, in mice leads to adipocyte hypertrophy and adiposity [17]. On the contrary, RA treatment results in weight loss and improves glucose tolerance [18]. In embryonic stem cells, RA promotes adipogenic program at the early stage of adipogenesis, before peroxisome proliferator activated receptor gamma (PPARG) functions [19]. In mature adipocytes, RA activates both retinoic acid receptors (RARs) and peroxisome proliferator activator receptor delta (PPARס) to enhance lipid oxidation and energy dissipation [18] which reduces lipid accumulation [20]. Correspondingly, RA administration to mice reduces obesity by upregulating uncoupling protein-1 (Ucpl) expression both in vivo and in vitro [16, 21, 22]. However, the role of RA on brown/beige adipogenesis and the underlying mechanisms have yet to be defined. Because RA increases the production of nitric oxide, an important mediator of angiogenesis, in vascular endothelial cells [23] and induces angiogenesis in vitro [24], we hypothesized that RA induces angiogenesis which subsequently promotes brown/beige adipogenesis. We previously found that maternal vitamin A supplementation promotes vascular development and increases adipose progenitors [25]. In the current study, we further explored the underlying mechanism by performing both in vivo and in vitro experiments.

\section{Results}

\section{$R A$ promotes in vitro angiogenesis of stromal vascular cells by stimulating VEGFA/VEGFR2 signaling}

The effects of RA on angiogenesis were tested in vitro using adipose tissue stromal vascular cells (SVCs), which contain both preadipocytes and endothelial progenitor cells [26]. Instead of two-dimensional culture system that allows limited cell-cell interactions, three-dimensional culture system were used to provide an appropriate environment for organogenesis in vitro [27]. Inguinal WAT (iWAT)-derived SVCs were cultured on matrigelcoated plates in endothelial basal medium supplemented with dimethyl sulfoxide (DMSO) or RA for 2 days. RA-treated cells produced and secreted more VEGFA to the medium (Figure 1a and b) and had higher mRNA level of Vegfa (Figure 1c). Because $1 \mu \mathrm{M}$ RA had the highest effects on both protein (Figure 1a and b) and mRNA levels (Figure 1c), this dose was used in the subsequent in vitro experiments. After seeding, SVCs aggregated and formed organoid colonies surrounded by capillary sprouts. The capillary sprouts continuously grew into the Matrigel and free cells migrated to expand the colony. Compared with the control group, RA substantially increased the number of colonies (Figure 1d; Supplementary Figure S1b). When Vegfr2 was knocked out by CRISPR/Cas9 (Supplementary Figure S1a), the number of cell colonies dramatically decreased (Figure 1d; Supplementary Figure S1b). In addition, RA also increased the number of capillary sprouts and promoted sprout elongation, which was absent in Vegfr2 null cells even in the presence of RA (Figure 1d; Supplementary Figure S1c and d). Notably, RA upregulated Vegfa in both WT and Vegfr2 null cells (Figure 1e). These data show that RA promotes angiogenesis of the organoids formed from adipose-derived SVCs by activating VEGFA/ VEGFR2 signaling.

To address why RA stimulates Vegfa expression, we analyzed putative RA response elements (RAREs) in the Vegfa promoter and found twelve putative sites (Figure 1f). RA increased the binding of RAR/retinoid $\mathrm{X}$ receptor to a number of sites (Figure $1 \mathrm{~g}$ ). We further mutated these sites on the Vegfa promoter luciferase reporter plasmid. The mutation of 4 putative RARE sites (pRARE) abolished the activation of Vegfa promoter stimulation by RA treatment (Figure 1h), showing that RA directly upregulates $V e g f a$ expression via multiple RAREs on its promoter region.

\section{$R A$ promotes brown adipogenesis in vitro through activating VEGFA/VEGFR2 signaling}

PDGFR $\alpha^{+}$marks adipose progenitors located in the perivascular region that can differentiate into both brown and white adipocytes. Before adipogenesis, SVC-formed colonies on Matrigel were stained with anti-PDGFR $\alpha$ antibody. More PDGFR $\alpha^{+}$cells were observed inside RA-treated colonies, and some of them migrated out of vessel boundaries (Figure 2a). After 6 days of angiogenesis on matrigel, to induce brown adipogenesis, cells were switched into DMEM medium supplemented with insulin and triiodothyroxine (T3) for 4 days. Cells were further cultured with insulin for 8 days. The capillary structures continued to extend into the Matrigel. At day 16, adipocytes were found both outside (Figure 2b) and within (Supplementary Figure S2a) capillaries. By day 18, more adipocytes outside the capillaries or colonies were observed (Figure 2b). We observed the loss of continuity between the capillary structure and adipocytes (Supplementary Figure S2b and c), and the presence of adipocyte clusters and free adipocytes suggests adipogenic progenitor proliferation and migration (Supplementary Figure S2b-d). More adipocytes were observed in the RA-treated group, which could 
a

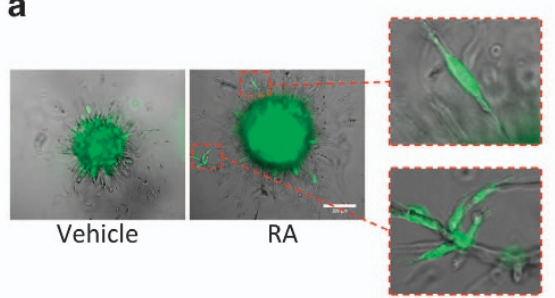

c

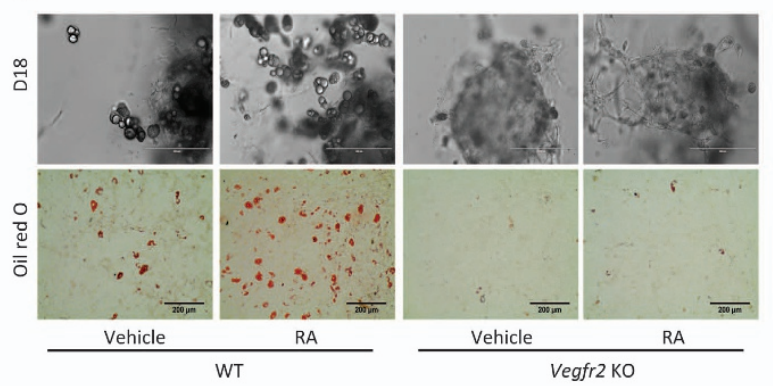

b

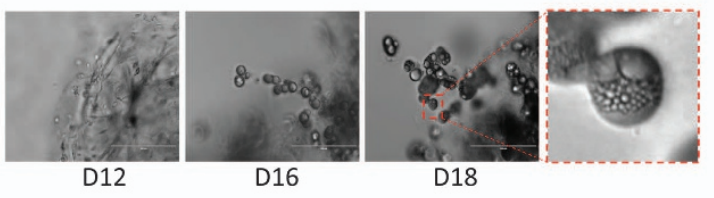

d

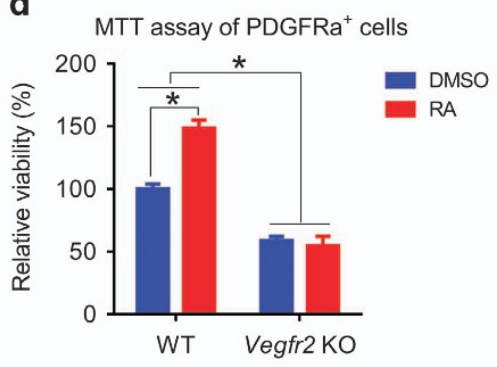

e

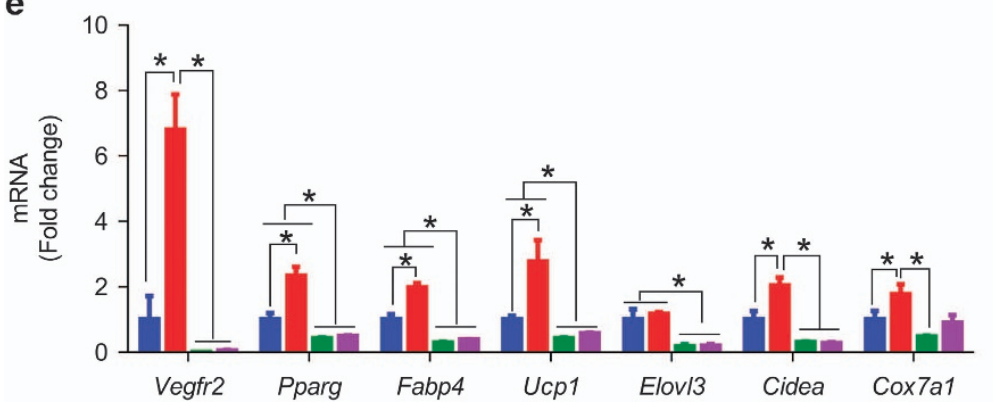

$\mathbf{f}$

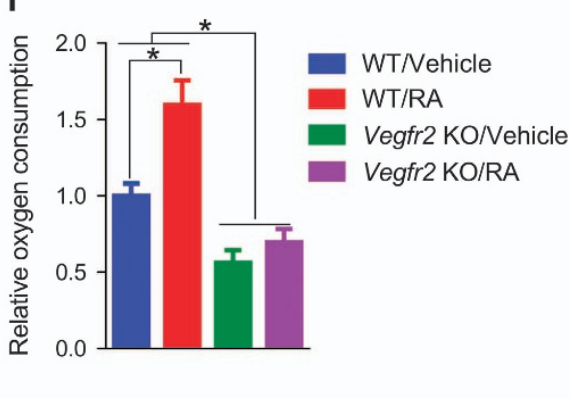

Figure 2 RA promotes brown adipogenesis in vitro through activating VEGFA/VEGFR2 signaling. Adipose-derived SVCs were cultured on Matrigel-coated plates in endothelial basal medium medium supplemented with either DMSO or RA for 6 days, then switched into DMEM medium supplemented with insulin and T3 for 4 days, and further cultured with insulin for 8 days. (a) PDGFR $\alpha^{+}$cells at D2. (b) Representative images of RA-treated cells at D12, D16 and D18. (c) Representative image of D18 control cells and Vegfr2 knockout cells treated with DMSO or RA (upper: bright field; lower: Oil-Red-O). (d) MTT assay of WT or Vegfr2 KO PDGFR $\alpha^{+}$cells treated with or without $1 \mu \mathrm{m}$ RA. (e) mRNA levels in D18 cells. (f) Oxygen consumption rate of cells. Data presented are mean \pm s.e.m., $n=6,{ }^{*} P<0.05$. Scale bar $=200 \mu \mathrm{m}$.

be due to increased PDGFR $\alpha^{+}$adipose progenitors (Figure 2c). Indeed, RA enhanced proliferation of PDGFR $\alpha^{+}$cells isolated from SVCs (Figure 2d). Vegfr2 null PDGFR $\alpha^{+}$cells had lower proliferation rates and did not respond to RA (Figure 2d), suggesting that RA increases PDGFR $\alpha^{+}$cells by activating VEGFA/VEGFR2 signaling. Vegfr2 null cells had abnormal capillary development, the capillary sprout rarely grew and very few adipocytes were formed (Figure 2c). After inducing brown adipogenesis, RA upregulated the expression of brown adipose genes including UCP1, Cidea and Cox7al, which were expressed at much lower levels in Vegfr2 null cells (Figure 2e). In line with the increased brown adipose genes, RA-treated cells had elevated oxygen consumption rates when compared with control cells
(Figure 2f). This suggests that RA-treated cells had a higher metabolic rate, which was not observed in Vegfr2 null cells (Figure 2f). In summary, these data show that RA, functioning through VEGFA/VEGFR2, promotes angiogenesis, increases PDGFR $\alpha^{+}$adipose progenitor cells and stimulates the development of beige adipocytes in vitro.

\section{$R A$ activates VEGF signaling to increase PDGFR $\alpha^{+}$ adipose progenitors in vivo}

In vivo, 1 week RA administration $\left(10 \mathrm{mg} \mathrm{kg}^{-1}\right.$ body weight (BW), injected every other day) increased blood vessel density in iWAT, reduced the size of adipocytes and induced the formation of multilocular beige adipocytes in WAT (Figure 3a and b). Consistently, RA upregulated the expression of angiogenic genes 
including Vegfa, Vegfrl, Vegfr2, epidermal growth factor $(E g f)$, fibroblast growth factor $2(F g f 2)$ in iWAT (Figure $3 \mathrm{c}$ ) and raised body temperature (Figure 3d and e). RA also upregulated the brown adipose genes in iWAT (Figure 3f). Because of the increased beige adipocytes, RA reduced serum triacylglycerols a

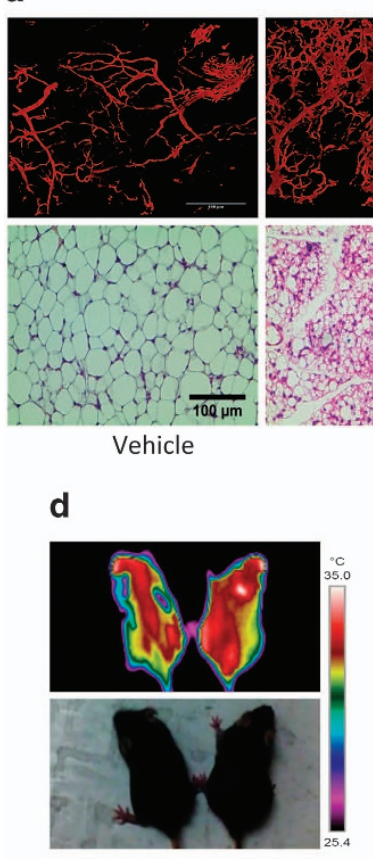

Vehicle RA e
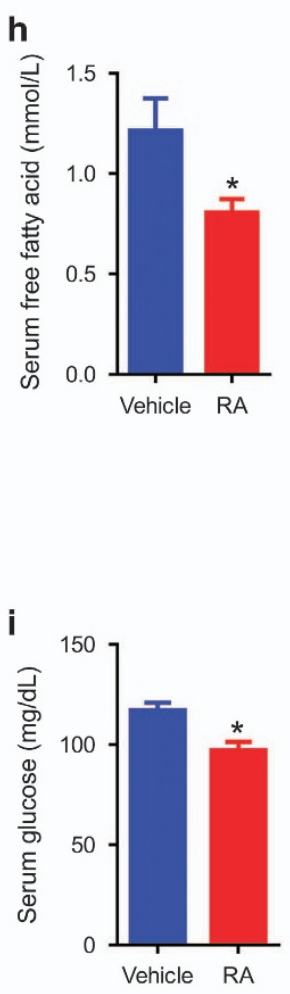

j b

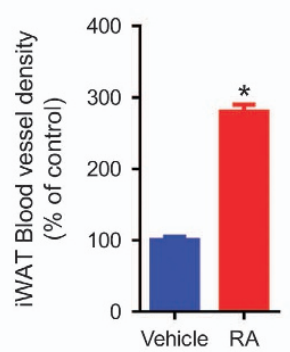

C

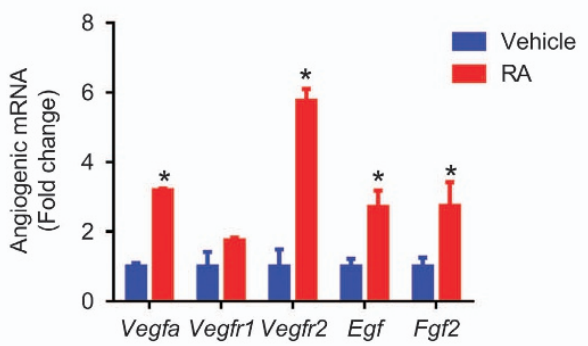

f

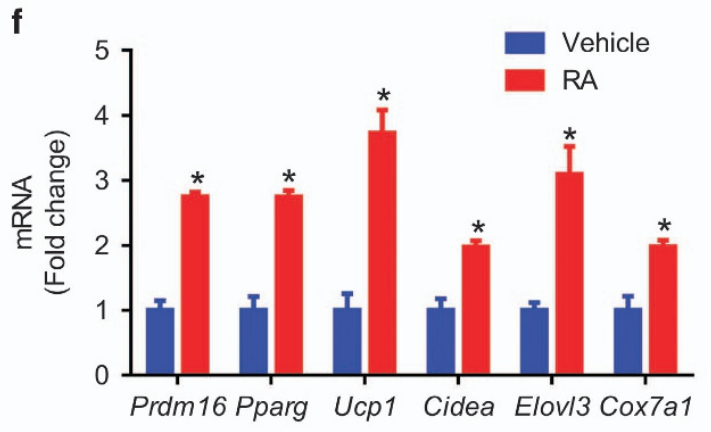

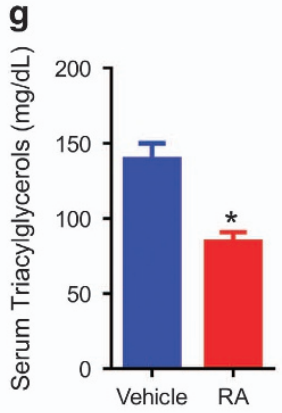
veride RA
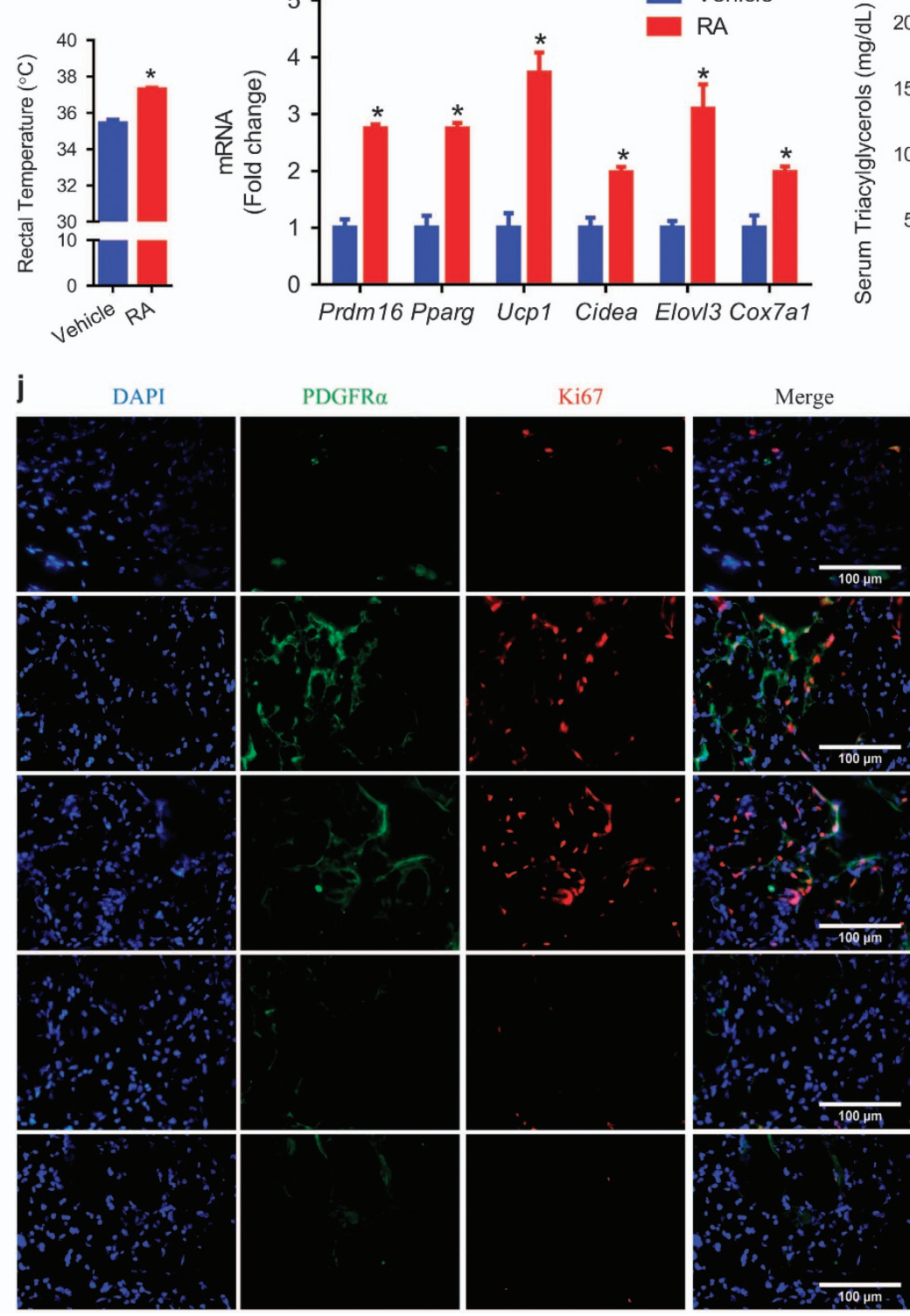

WT/Vehicle

WT/RA

WT/VEGF164

$\mathrm{P}-\mathrm{V}-\mathrm{KO} /$ Vehicle

$\mathrm{P}-\mathrm{V}-\mathrm{KO} / \mathrm{RA}$ 
(Figure 3g), free fatty acids (Figure 3h) and glucose (Figure 3i). As showed by IHC staining, RA and an isoform of the mouse recombinant VEGFA, VEGF164, increased the proliferation of PDGFR $\alpha^{+}$ cells in iWAT of WT (wild type, C57BL6) mice. In PDGFR $\alpha$ CreER-VEGFR2 $2^{\text {loxP }}$ (P-V-KO) mice, in which VEGFR2 was conditionally knocked out in PDGFR $\alpha^{+}$cells, RA showed no effects on proliferation of PDGFR $\alpha^{+}$cells (Figure 3j; Supplementary Figure S3). In summary, in vivo RA injection induced WAT browning which is accompanied with increased blood vessel density. RA increased adipose progenitors by activating VEGFA/VERGFR2 signaling.

\section{$R A$ promotes the differentiation of PDGFR $\alpha$-positive cells into beige adipocytes in vivo}

To examine the fate of $\mathrm{PDGFR}^{+}$adipose progenitor cells after RA treatment, we developed PDGFR $\alpha$ tracking mice (Figure $4 \mathrm{a}$ ) using two transgenic lines: PDGFR $\alpha$ CreER and ROSA ${ }^{\mathrm{mT} / \mathrm{mG}}$ mice. Without tamoxifen, all cells in PDGFR $\alpha$ tracking mice express tdTomato with red fluorescence. Following tamoxifen (100 $\mathrm{mg} \mathrm{kg}^{-1} \mathrm{BW}, 24 \mathrm{~h}$, Figure 4b) administration, the $\mathrm{mT}$ cassette was deleted in Cre-expressing cells allowing for GFP expression. GFP positive cells were found on blood vessels and adipose tissue (Figure 4c; Supplementary Videos S1-S3). Then, mice were treated with RA (Figure 4b), and after 1 week, the amount of PDGFR $\alpha^{+}$cells decreased and some GFP labeled adipocytes were observed (Figure $4 \mathrm{c}$ and $\mathrm{f}$ ), indicating that the perivascular PDGFR $\alpha^{+}$cells at least partially differentiated into adipocytes. To determine whether PDGFR $\alpha^{+}$cells would be replenished, PDGFR $\alpha$ lineage tracing mice were further administered with tamoxifen at day 7 (D7) and D14 respectively, so that newly generated PDGFR $\alpha^{+}$cells would be labeled with GFP (Figure 4d). The population of PDGFR $\alpha^{+}$cells was constantly present (Figure 4e) despite a portion of PDGFR $\alpha^{+}$cells that differentiated into adipocytes (Figure 4e and f). These data showed that PDGFR $\alpha^{+}$cells on blood vessels are capable of self-renewal and a small portion of PDGFR $\alpha^{+}$cells can differentiate into adipocytes spontaneously. Furthermore, we did whole mount tissue or tissue section immunohistochemical staining using anti-UCP-1 antibody. Those adipocytes derived from PDGFR $\alpha^{+}$cells were UCP-1 positive (Supplementary Figure S4a and $b$ ), showing their beige adipocyte identity. These data suggest that, RA signaling activates the differentiation of PDGFR $\alpha^{+}$cells, on or around blood vessels, into beige adipocytes.

\section{VEGF signaling is required for RA-induced WAT browning}

VEGF is known to regulate metabolic homeostasis [10], modulate cold tolerance and energy expenditure [28]. Consistent with previous studies, 1 week of VEGF164 injections $\left(2 \mu \mathrm{g} \mathrm{kg}^{-1} \mathrm{BW}\right.$, once per two days) induced iWAT browning (Supplementary Figure S5a) and thermogenic activities (Supplementary Figure S5b and c). VEGF164 upregulated the expression of brown/beige adipose genes Prdm16, Ucp1, Elovl3 and Cox7al (Supplementary Figure S5d). Although PDGFRa is expressed in other mesenchymal populations, PDGFRaCre mouse line was identified as an efficient model for adipose lineage tracing and can be used for gene ablation at the level of adipose progenitors [29-31]. When Vegfr2 was knocked out in PDGFR $\alpha^{+}$cells, RA failed to induce WAT browning (Figure 5a), thermogenesis (Figure 5b) and expression of adipose genes (Figure 5c). Moreover, 1 week of VEGF164 injection $\left(2 \mu \mathrm{g} \mathrm{kg}^{-1} \mathrm{BW}\right.$, once per two days) on PDGFR $\alpha$ tracking mice induced adipogenic differentiation of PDGFR $\alpha^{+}$cells (Figure $5 \mathrm{~d}$ and e). Fewer PDGFR $\alpha^{+}$cells differentiated into adipocytes upon RA injection when Vegfr2 was conditionally knocked out (Figure 5d and e). These data proved that VEGF signaling in PDGFR $\alpha^{+}$adipose progenitor cells is required for RA-induced WAT browning.

\section{$R A$ and VEGF signaling in brown adipogenesis of P19 embryo stem cell line}

Embryo bodies (EBs) formed by P19 embryonal carcinoma stem cells have the capacity to differentiate into three germ layer cells [32], and have been used for

Figure 3 RA activates VEGF signaling to increase PDGFR $\alpha+$ adipose progenitors in vivo. C57BL6 mice were injected with RA (10 $\mathrm{mg} \mathrm{kg}^{-1} \mathrm{BW}$ injected every other day) for 1 week. (a) Representative images showing blood vessel and adipocytes in iWAT. (b) Quantification of blood vessel density. (c) Angiogenic gene expression in iWAT. (d) Surface temperature. (e) Rectal temperature. (f) Brown adipose gene expression in iWAT. (g) Serum triacylglycerols. (h) Serum-free fatty acids. (i) Serum glucose. (j) Proliferating (Ki67 labeled) and PDGFR $\alpha$-positive cells in iWAT of WT and P-V-KO (PDGFR $\alpha$ CreER-VEGFR2 ${ }^{\text {loxP }}$ ) conditional VEGFR2 knockout mice in response to 1 week of RA (10 mg kg $\left.{ }^{-1} \mathrm{BW}\right)$ or VEGF164 $\left(2 \mathrm{\mu g} \mathrm{kg}^{-1} \mathrm{BW}\right.$ ) injection (injected every other day, and same doses for other in vivo experiments if unstated). Data presented are mean \pm s.e.m., $n=6,{ }^{*} P<0.05$. Scale bar $=100 \mu \mathrm{m}$. 
a

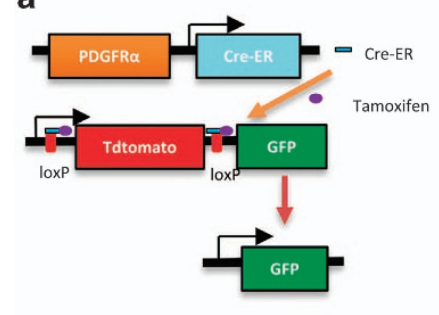

b

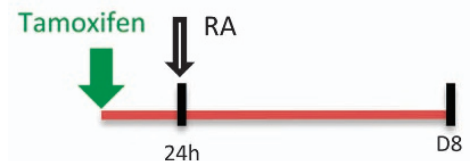

c

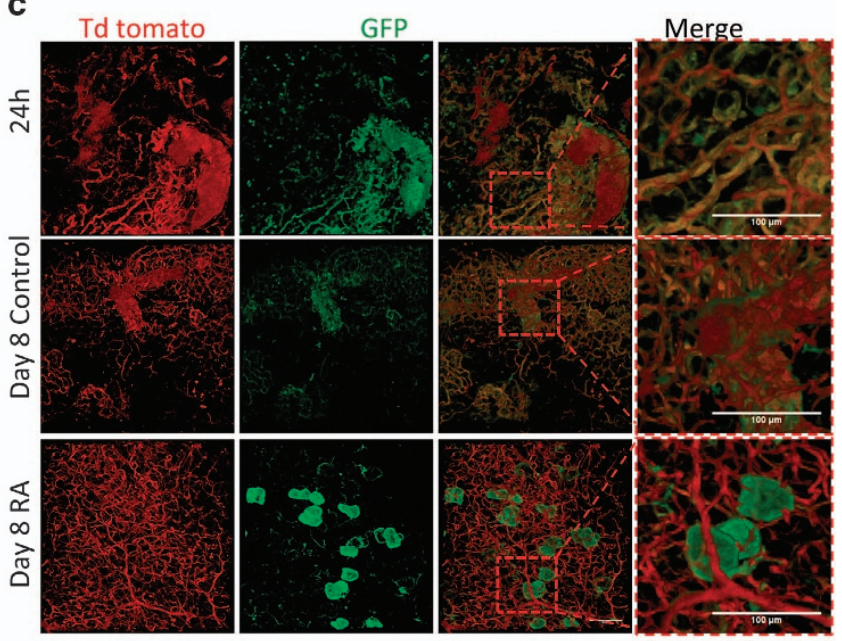

d

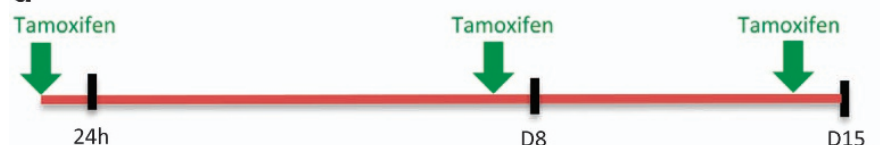

e
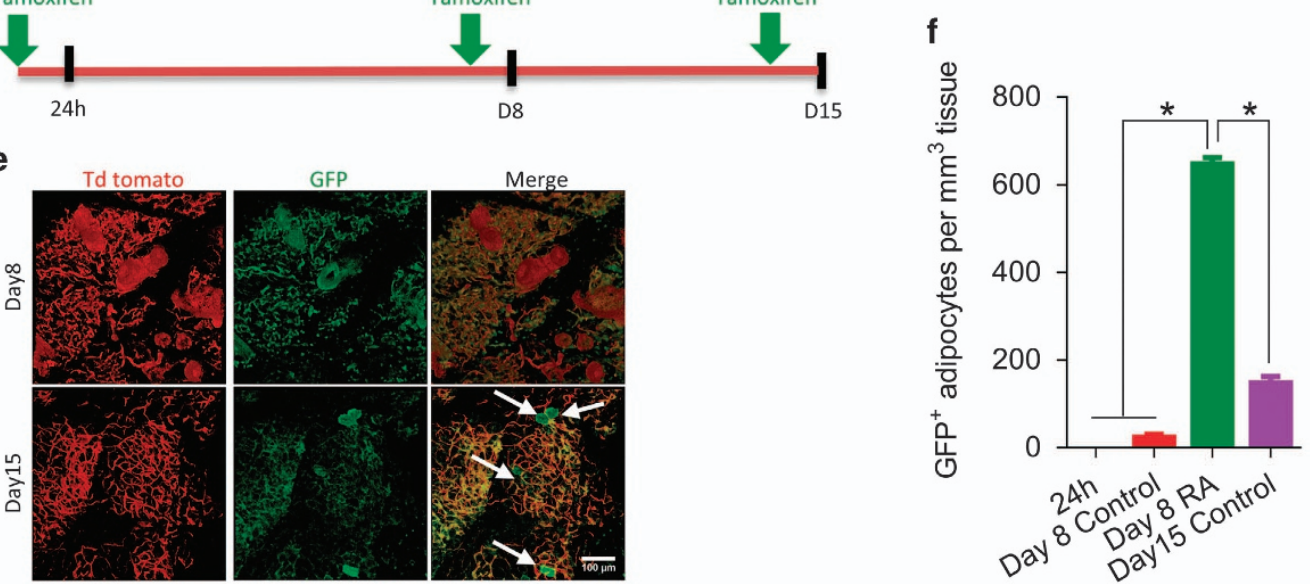

Figure 4 RA promotes the differentiation of PDGFR $\alpha$-positive cells into beige adipocytes in vivo. (a) PDGFR $\alpha$ tracking mice. (b) Graph showing time points of tamoxifen and RA treatment. (c) PDGFR $\alpha$ tracking mice were injected with tamoxifen, then injected with vehicle (DMSO) or $10 \mathrm{mg} \mathrm{kg}^{-1}$ BW RA $24 \mathrm{~h}$ later. Representative images show blood vessels (red) and PDGFR $\alpha^{+}$ cells (green) in iWAT of PDGFR $\alpha$ tracking mice at different time points. (d) Graph showing time points of tamoxifen and RA treatment. (e) Representative images of blood vessels and PDGFR $\alpha^{+}$cells in iWAT of PDGFR $\alpha$ tracking mice injected with tamoxifen once every week. (f) Quantification of GFP ${ }^{+}$adipocytes. Data presented are mean \pm s.e.m., $n=6,{ }^{*} P<0.05$. Scale bar $=100 \mu \mathrm{m}$.

studying early differentiation of adipocytes [19] and endothelial cells [33], and morphogenesis of adipose tissue [19]. RA-treated EBs had higher expression of Vegfa, Vegfrl and Vegfr2, which was downregulated in BMS493, a pan-retinoic acid receptor inverse agonist, treated EBs (Supplementary Figure S6a). Moreover, more VEGFR2 positive cells (Supplementary Figure S6b) and increased cell expansion (Supplementary Figure S6c) were found in the RA-treated group. Using P19 cells, we explored the interaction between RA and VEGF signaling on early brown adipogenic differentiation.

We treated P19 embryo bodies with RA and/or $10 \mathrm{~nm}$ VEGF164, as well as DMSO (control) for 3 days
(Figure 6a). Brown adipogenesis was then induced using insulin and T3. After 4 days, RA dramatically increased Prdml6 and Pparg expression (Figure 6b). When combined with RA, VEGF164 showed synergistic effects on the expression of brown adipogenic genes (Figure 6b). Similarly, RA increased PRDM16 protein level and VEGF164 showed similar but much weaker effects on PRDM16 (Figure 6c; Supplementary Figure S6d). Although VEGF164 upregulated brown adipogenic genes, only small lipid droplets were accumulated in VEGF164-treated cells which showed no difference to the control cells (Figure 6d). Embryo bodies pretreated with RA differentiated into adipocytes with dramatically larger lipid droplets 
a

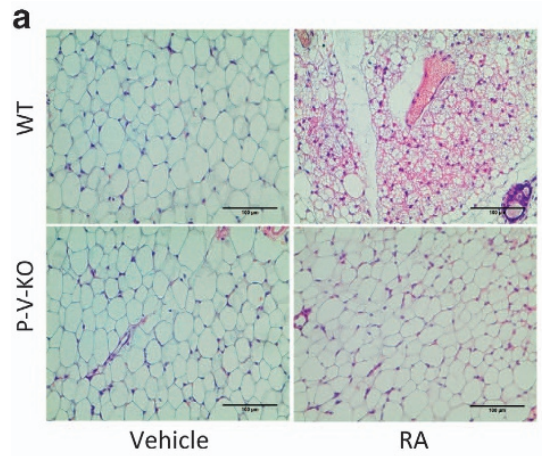

b

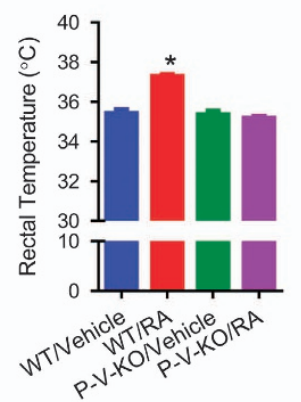

d

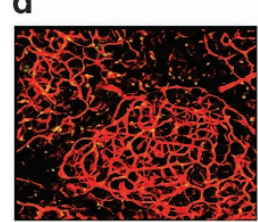

Vehicle

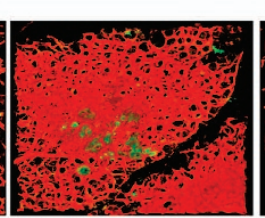

VEGF164

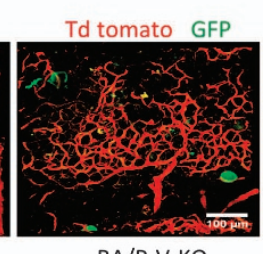

RA/P-V-KO c

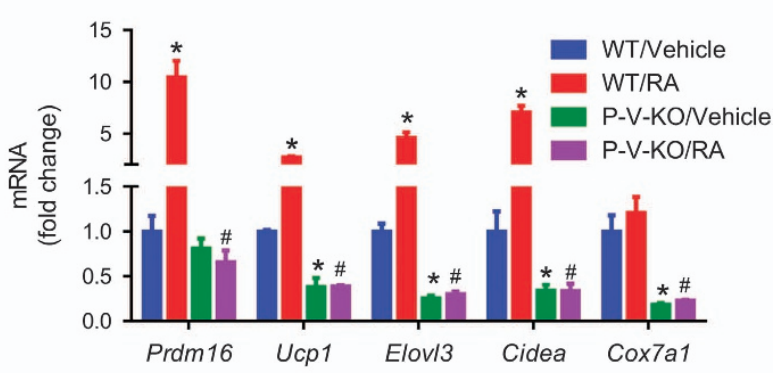

e

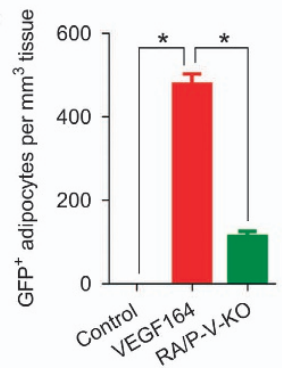

Figure 5 VEGF signaling mediates beige adipogenesis stimulated by RA in vivo. (a) Representative images of H\&E stained iWAT adipocytes in WT and P-V-KO mice injected with vehicle or RA for 1 week, (b) rectal temperature, and (c) mRNA levels in iWAT of WT and P-V-KO mice treated with RA for 1 week ( ${ }^{*}$ compared with WT/Vehicle, " compared with P-V-KO/Vehicle). (d) Representative images of iWAT and (e) frequency of GFP ${ }^{+}$cells in PDGFR $\alpha$ tracking mice treated with VEGF164 or RA for 1 week. Data presented are mean \pm s.e.m., $n=6$, * or ${ }^{\#} P<0.05$. Scale bar $=100 \mu \mathrm{m}$.

(Figure 6d). We further identified the P19 cells-derived adipocytes as brown adipocytes (Supplementary Figure S6e). These data suggest that RA committed the pluripotent cells into brown adipocyte precursors. Using CRISPR/Cas9 system, we knocked out VEGFR2 in P19 cells. The effects of RA on Prdm16 expression was partially abolished by VEGFR2 ablation (Figure 6e). VEGFA, together with RA, upregulates Prdm16 expression. However, VEGFa alone is insufficient to induce the adipogenic program of stem cells.

\section{$R A$ and VEGF activate p38MAPK to recruit $R A R$ to the prdm16 promoter}

We further explored whether RA and VEGF164 promote Prdml6 expression through activation of p38MAPK. P19 EBs were treated with RA or VEGF164 in presence or absence of $10 \mu \mathrm{M}$ SB203580, the p38MAPK inhibitor. Both RA and VEGF164 increased PRDM16 and phosphorylated p38MAPK protein levels (Figure 7a). SB203580 completely abolished p38MAPK activation and PRDM16 expression (Figure 7a), showing that p38MAPK mediates Prdm16 expression stimulated by RA.

P38MAPK phosphorylates RAR $\alpha$ and directs it to target promoters [34]. Here we identified two RARE sites on Prdm16 promoter (pRARE C and pRARE E, Figure $7 \mathrm{~b}$ and c; Supplementary Figure S7b) and confirmed that activation of p38MAPK is related to phosphorylation of RAR (Supplementary Figure S7a). P38MAPK activation by anisomysin, RA or VEGF164 increased the binding of RAR to RAREs on the Prdm16 promoter whereas p38MAPK inhibition by SB203580 eliminated the effects of RA or VEGF164 on RAR binding (Figure 7d-f). Moreover, in the presence of an RAR $\alpha$ selective antagonist, ER50891 [35], anisomysin, VEGF164 or RA failed to upregulate Prdm16 expression (Figure 7g).

\section{Discussion}

RA signaling acted as a central regulator of adipose tissue remodeling and adipocyte differentiation that is required for the process of WAT browning. (1) RA upregulated the expression of VEGFA which further increased the number of blood vessels in WAT. (2) RA and VEGF induced beige adipogenesis of PDGFR $\alpha^{+}$ adipose precursor cells. (3) RA upregulated the transcription of Prdml6 to trigger the commitment of pluripotent stem cells into brown adipocyte precursors. Both RA and VEGF signaling activated p38MAPK and further enhanced the binding of RAR to RAREs 
a

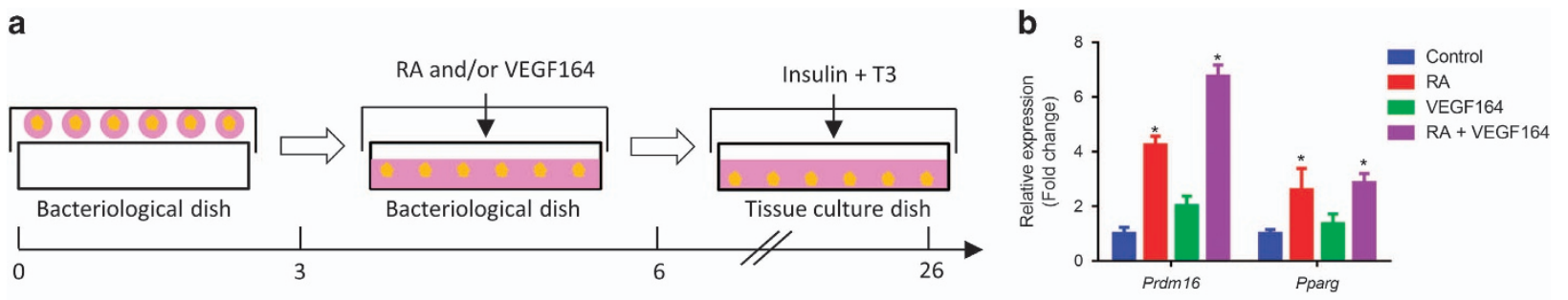

c

d
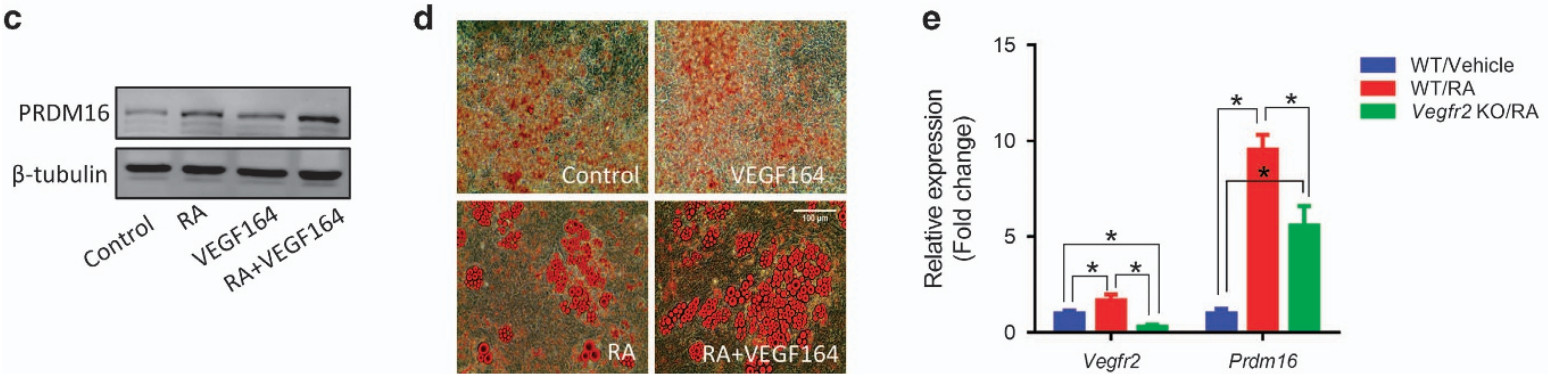

Figure 6 RA and VEGF signaling in brown adipogenesis of P19 embryo stem cell line. (a) P19 embryo bodies were formed in hanging drops then treated with VEGF164 (10 nM, same dose for other in vitro experiments if unstated) or RA for 3 days, then underwent brown adipogenesis for 26 days. (b) Prdm16, Pparg mRNA and (c) PRDM16 protein after treated with RA or VEGF164 for 3 days. (d) P19 cell-derived adipocytes stained by Oil-Red O. Scale bar $=100 \mu \mathrm{m}$. (e) The expression of Vegfr2 and Prdm16 in WT and Vegfr2 KO p19 cells in the presence or absence of RA during brown adipogenesis. Data presented are mean \pm s.e.m., $n=3,{ }^{*} P<0.05$.

on the promoter of $\operatorname{Prdm16}$, driving brown/beige adipogenesis of progenitor cells.

As an endothelial growth factor, VEGF is well known to induce cell proliferation [36]. In this study, we found RA signaling activates downstream VEGFVEGFR2 to promote proliferation of PDGFR $\alpha^{+}$ progenitors. Blood vessel walls may be integral to the origin of mesenchymal stem cells and other adult stem cells because of the pluripotency of perivascular cells which is similar to that of mesenchymal stem cells [13]. Besides pericytes, endothelial cells which are traced by VE-cadherin give rise to both white and brown adipocytes [14]. Other adipose progenitor cells like PDGFR $\alpha^{+}$[37] and PDGFR $\beta^{+}$cells are also perivascularly located. Besides enhanced cell proliferation, the increased angiogenesis under RA treatment would also contribute to the increase of adipose progenitors.

Angiogenesis is associated with adipose development [7]. However, controversy exists regarding the role of angiogenesis in obesity development. Angiogenesis inhibitors reduce body weight [38, 39] while VEGF overexpression prevents adiposity [10]. Enhanced angiogenesis increases energy expenditure in the metabolically active adipose tissue, while in the metabolically quiescent obese individuals with a large amount of WAT, it is therapeutically beneficial to inhibit angiogenesis [7]. Our data showed that VEGFA promotes the proliferation of $\mathrm{PDGFR} \alpha^{+}$precursor cells, although VEGFA had synergistic effects on Prdm16 expression by activating p38MAPK, itself is unable to activate Prdm16 transcription which relies on binding of RA to RAR. The activated VEGFA signaling and increased adipose vascularity provide cells which can differentiate into beige (anti-obesity) or white (pro-obesity), and RA is important in driving these cells to differentiate into beige adipocytes to prevent obesity (Figure 8).

\section{Materials and Methods}

\section{Antibodies and chemicals}

Antibodies against $\beta$-tubulin (\#2146), p38 (\#9212), Phosphop38 (\#4511), p38 (\#9212) were purchased from Cell Signaling (Danvers, MA, USA), UCP1 (cat. no. PA1-24894), PRDM16 (cat. no. PA5-20872) and VEGFA (cat. no. PA1-16948) from Thermo Fisher Scientific (Waltham, MA, USA). PDGFR $\alpha$ (cat. no. 1062-PR) from R\&D. Alexa Fluor 488 anti-mouse CD309 (cat. no. 136408), APC anti-mouse CD140a (cat. no. 135908), $\mathrm{PE} / \mathrm{Cy} 7$ anti-mouse CD45 (cat. no. 103114) from Biolegend (San Diego, CA, USA). Antibody against ZFP423 (sc-48785) was purchased from Santa Cruz Biotech (Dallas, TX, USA).

1,1'-Dioctadecyl-3,3,3', $3^{\prime}$-tetramethylindocarbocyanine perchlorate (42364), tamoxifen (T5648), all-trans-retinoic acid (R2625), 4-hydroxytamoxifen (H7904), insulin (I3536), dexamethasone (D4902), 3-isobutyl-1-methylxanthine (I5878), triiodothyronine (T3) (IRMM469) and Oil-Red O (O0625) were purchased from Sigma (St Louis, MO, USA). BMS493 (cat. no. 3509) was purchased from Tocris Bioscience (Ellisville, MO, 
a

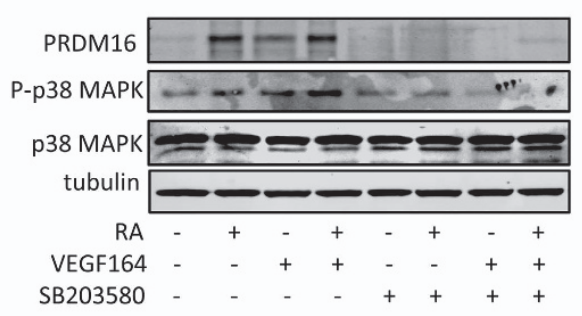

b

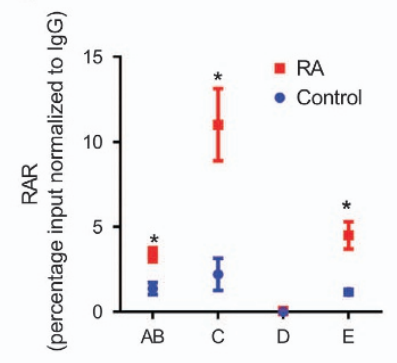

C

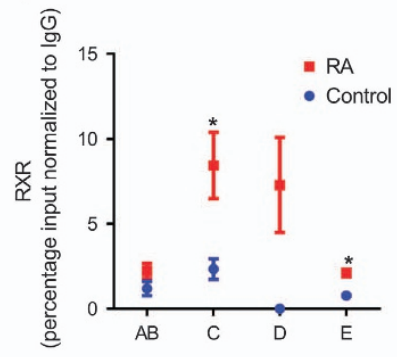

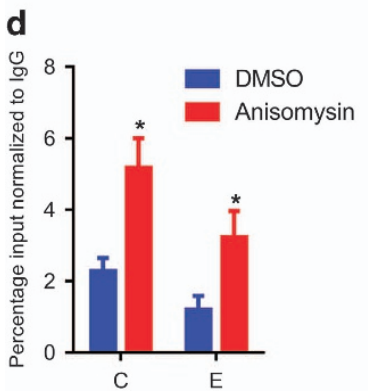
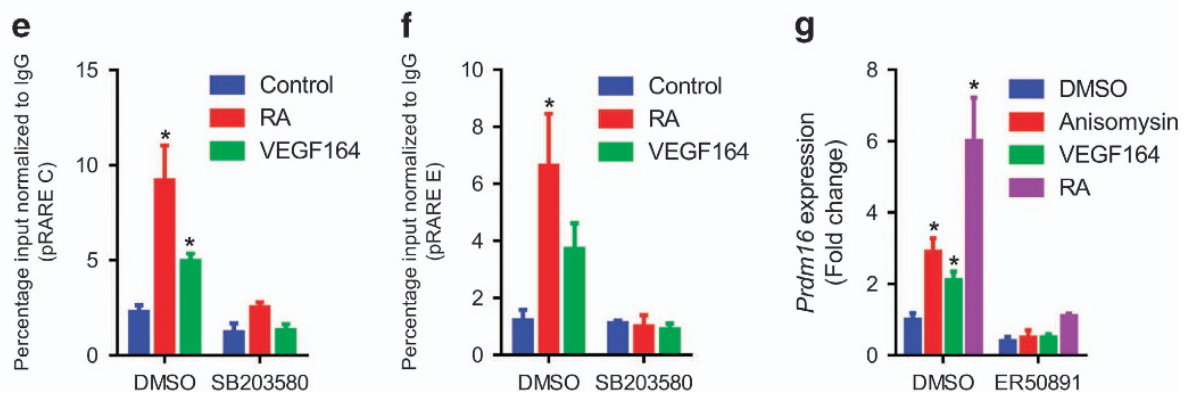

Figure 7 RA and VEGF activate p38MAPK to recruit retinoic acid receptor (RAR) to the Prdm16 promoter. (a) PRDM16, phosphop38MAPK and p38MAPK proteins in P19 embryo bodies treated with indicated chemicals for 3 days. (b, c) P19 embryo bodies were treated with RA or DMSO for $4 \mathrm{~h}$, and binding of RAR and retinoid $\mathrm{X}$ receptor (RXR) to putative RAR response elements (pRAREs) were analyzed by ChIP. (d) Binding of RAR to pRARE \#C and \#E in embryo bodies (EBs) treated with DMSO or anisomysin for $4 \mathrm{~h}$. (e, f) Binding of RAR to pRARE \#C and \#E in EBs treated with DMSO, SB203580, RA or VEGF164 for $4 \mathrm{~h}$. (g) Expression of Prdm16 in EBs treated with indicated chemicals for 4 h. Data presented are mean \pm s.e.m., $n=3,{ }^{*} P<0.05$.

USA). Mouse recombinant VEGF164 (cat. no. 583106) was purchased from Biolegend (San Diego, CA, USA).

\section{Adipose-derived stromal vascular cell isolation, cell culture and induction of adipogenesis}

Stromal vascular cells were isolated from iWAT as previously described [25]. Cells were seeded on 24-well culture dishes precoated with $200 \mu \mathrm{l}$ of Matrigel $\left(8 \mathrm{mg} \mathrm{m}^{-1}\right)$ and covered with $500 \mu 1$ endothelial basal medium supplemented with $10 \%$ FBS for 6 days. Brown adipogenesis was then induced by $10 \% \mathrm{FBS} /$ DMEM supplemented with $2 \mu \mathrm{g} \mathrm{ml}^{-1}$ insulin and $2 \mathrm{nM} \mathrm{T} 3$ for 6 days. Differentiated cells were fixed in 4\% PFA for $10 \mathrm{~min}$ at room temperature and rinsed 3 times with PBS. Fixed cells were stained with Oil-Red O solution for 10 min then rinsed with PBS to remove excessive Oil-Red $\mathrm{O}$ dye. Following microscopic observation, Oil-Red $\mathrm{O}$ dye retained in cells were solubilized with isopropanol and the light absorbance was measured at $510 \mathrm{~nm}$ using a Synergy H1 Multi-Mode Reader (BioTek, Winooski, VT, USA). For gene expression, before mRNA and protein extraction, cells were incubated with $0.5 \mathrm{U} \mathrm{ml}^{-1}$ Dispase in the medium for $30 \mathrm{~min}$ at $37^{\circ} \mathrm{C}$ to dissolve the Matrigel.

PDGFR $\alpha^{+}$cells were isolated from stromal vascular cells of inguinal WAT using a manual magnetic cell separation system (Miltenyi Biotec, Bergisch Gladbach, Germany). Isolated PDGFR $\alpha^{+}$cells were cultured on a $10 \mathrm{~cm}$ dish for $24 \mathrm{~h}$, then seeded into 96-well plates ( 2000 cells per well) and cultured for $24 \mathrm{~h}$. For analyzing cell proliferation, cells were incubated with sterile 3-(4,5-dimethythiazol-2-yl)-2,5-diphenyltetrazoliumbromide
(MTT, Sigma, $0.5 \mathrm{mg} \mathrm{ml}^{-1}$ in medium) for $4 \mathrm{~h}$ at $37^{\circ} \mathrm{C}$. The culture medium was removed afterwards and $100 \mu \mathrm{l}$ of DMSO was added to each well. The mixture was further incubated at $37^{\circ} \mathrm{C}$ for $10 \mathrm{~min}$ and the absorbance was measured at $570 \mathrm{~nm}$ using the Synergy H1 Multi-Mode Reader (BioTek, Winooski, VT, USA).

Proteins in cell culture medium were precipitated using chloroform and methanol. Briefly, 1 volume $(V)$ of methanol and $1 / 4 V$ of chloroform was added to the medium, mixed and centrifuged at $12000 \times g$ for $10 \mathrm{~min}$. The methanol layer was discarded (upper layer) and then $1 \mathrm{~V}$ of methanol was added and centrifuged at $12000 \times g$ for $10 \mathrm{~min}$. The supernatant was then discarded and the resulting pellet was air dried for subsequent western blot analysis.

\section{Adipogenesis of P19 cells}

Hanging drops containing $10^{3} \mathrm{P} 19$ cells in $25 \mu 1$ medium were maintained for 3 days on the lids of bacteriological dishes. The embryoid bodies (EB) formed were then transferred into bacteriological dishes in suspension in a medium supplemented with DMSO, all-trans RA or VEGF164 for 3 days [19]. EBs were then transferred to tissue culture plates along with differentiation medium supplemented with $2 \mu \mathrm{g} \mathrm{ml}^{-1}$ insulin and $2 \mathrm{~nm}$ triiodothyroxine (T3) for 20 days.

\section{Oxygen consumption assay}

Oxygen consumption was measured using a Thermo Scientific Orion 3-Star Dissolved Oxygen Meter (Thermo Electron Corporation, Madison, WI, USA). Fresh culture medium was 


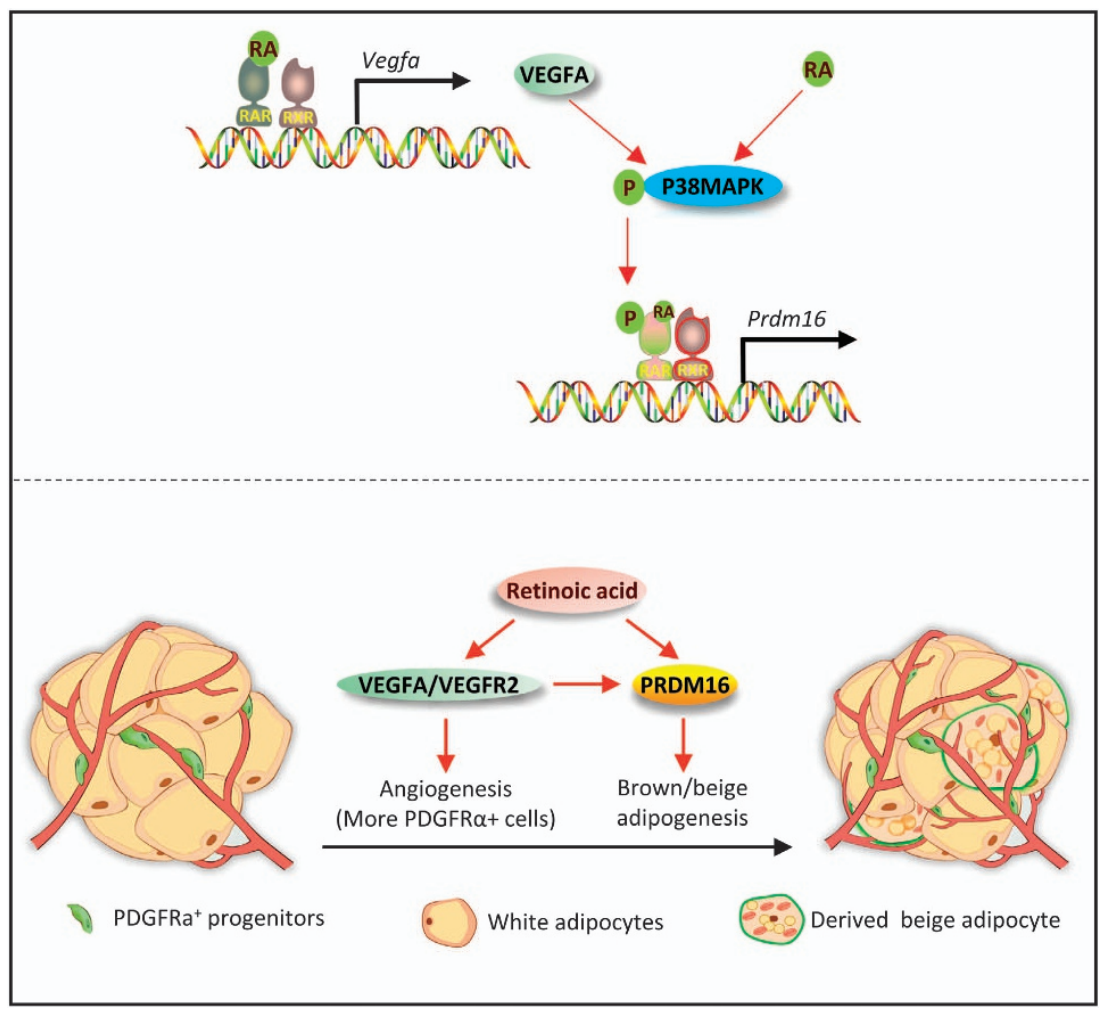

Figure 8 Schematic illustration showing the mechanism of RA-induced WAT browning. Upper: RA binds to RAR/retinoid X receptor heterodimer to activate Vegfa promoter. VEGFA and RA activate P38MAPK, and P38MAPK phosphorylates RAR and directs it to the Prdm16 promoter. Lower: RA activates VEGFA/VEGFR2 signaling to stimulate angiogenesis and increases PDGFR $\alpha^{+}$cells; RA and VEGFA/VEGFR2 signaling upregulates Prdm16 to induce white adipose tissue browning.

added to the plates, and the dissolved oxygen concentration was measured at the start and after $30 \mathrm{~min}$ incubation.

\section{CRIPSR/Cas9 gene editing}

CRIPSR/Cas9 plasmid expressing a gRNA targeting $V e g f r 2$ (CRISPR sequence: GTCCCGGTACGAGCACTTGT, Vector: PX458 [40]) and scrambled sequence (CRISPR sequence: GCACTACCAGAGCTAACTCA, Vector: PX458) was generated by GenScript Inc (Piscataway, NJ, USA). All plasmids used in this study were delivered to cells using a Lipofectamin 3000 Reagent (cat. no. L3000015; Thermo Fisher Scientific).

\section{Bioinformatics and chromatin immunoprecipitation assay}

The ChIP assay was performed as previously described [41]. Briefly, the protein-DNA complexes were crosslinked by incubating the cells with $1 \%$ formaldehyde solution for $10 \mathrm{~min}$ at room temperature (RT). Then, the formaldehyde was quenched by $125 \mathrm{~mm}$ glycine for $5 \mathrm{~min}$ at RT. Cells were then lysed in a cold lysis buffer ( $1 \%$ SDS, $10 \mathrm{mmol}^{-1}$ Tris- $\mathrm{HCl}, \mathrm{pH} 8.0$, $10 \mathrm{mmol} \mathrm{l}^{-1} \mathrm{NaCl}, 3 \mathrm{mmol}^{-1} \mathrm{MgCl}_{2}$ and $0.5 \% \mathrm{NP}-40$ ) containing a protease inhibitor cocktail (Thermo Fisher Scientific). The samples were then sonicated to shear chromatin to an average length of about $1 \mathrm{~kb}$. After centrifugation at $12000 \times \mathrm{g}$ for $10 \mathrm{~min}$, the supernatant was pre-cleaned with protein A beads (Thermo Fisher Scientific) and then incubated with antibodies against RAR, retinoid X receptor, or normal rabbit IgG overnight at $4{ }^{\circ} \mathrm{C}$. Then, the antibody-chromatin complex was precipitated with protein A beads, further treated with RNaseA and then proteinase $\mathrm{K}$ for $2 \mathrm{~h}$ to remove RNA and protein respectively. DNA was purified with ChIP DNA Clean \& Concentrator (Zymo Research). The putative RAREs in the Vegfa and Prdml6 promoters were predicted (Supplementary Tables S2 and S5) using the JASPAR database (http://jaspardev. genereg.net/). Primers covering these sites are listed in Supplementary Tables S3 and S6.

\section{Plasmid DNA mutation and luciferase activity assay}

The wild type Vegf-luc plasmid (\#27987) was purchased from Addgene (Cambridge, MA, USA). Vegfa promoter mutations were performed using a Q5 Site-Directed Mutagenesis Kit (NEB, Ipswich, MA, USA). The mutagenic primers were designed using the NEB online primer design software NEBaseChanger (http://nebasechanger.neb.com), these primers are listed in Supplementary Table S4. Luciferase activity was measured using the Dual-Luciferase Reporter Assay System (Promega, cat. no. E1910).

Mice

Animal studies were conducted in AAALAC-approved facilities according to protocols approved by the Institutional Animal Care and Use Committee (IACUC) at Washington State University. C57BL/6 mice, PDGFR $\alpha$ CreER (stock 
number: 018280), VEGFR2 ${ }^{\text {loxP }}$ (stock number: 018977), and R26CreER mice (stock number 004847) and ROSA ${ }^{\mathrm{mT/mG}}$ mice (stock number: 007676) mice were purchased from the Jackson Laboratory (Bar Harbor, ME). R26-RAR $\alpha 403$ mice were kindly provided by Dr Cathy Mendelsohn [42]. All mice were fed with a diet containing $15 \mathrm{IU} \mathrm{g}^{-1}$ Vitamin A (Teklad global diet 2018).

Retinoic acid (10 $\left.\mathrm{mg} \mathrm{kg}^{-1} \mathrm{BW}\right), \mathrm{BMS} 493\left(10 \mathrm{mg} \mathrm{kg}^{-1} \mathrm{BW}\right)$ or vehicle (DMSO) dissolved in corn oil were intraperitoneally injected once per two days for mouse experiments. VEGF164 was dissolved in phosphate-buffered saline (PBS) at a dose of $2 \mu \mathrm{g} \mathrm{kg}^{-1} \mathrm{BW}$ per injection [43]. PDGFR $\alpha$ tracking mice were given a single intraperitoneal injection of $100 \mathrm{mg} \mathrm{kg}^{-1} \mathrm{BW}$ tamoxifen to label PDGFR $\alpha^{+}$cells. Conditional knockouts were induced by daily intraperitoneal injection of $25 \mathrm{mg} \mathrm{kg}^{-1} \mathrm{BW}$ tamoxifen for three days. Mice lacking Cre or lox genes were used as the WT control for transgenic mice; both control and Cre-lox mice were injected with tamoxifen. The doses of chemicals were determined by our preliminary experiments.

\section{Intraperitoneal glucose tolerance test}

Following 6 h-fasting, mice were administered $2 \mathrm{~g} \mathrm{~kg}^{-1}$ BW D-glucose. Blood samples were collected from the tail veil at $0,15,30,60,90$ and $120 \mathrm{~min}$ post injection and glucose concentration was measured using a glucose meter (Bayer Contour, Tarrytown, NY, USA). The area under the curve was calculated.

\section{Tissue processing and histology}

Blood vessels were labeled with 1,1'-dioctadecyl-3,3,3',3'tetramethylindocarbocyanine perchlorate (DiI) [44]. Briefly, mice were euthanized by $\mathrm{CO}_{2}$, then sequentially perfused with PBS, DiI and 4\% PFA into left ventricle (open the right atrium before perfusion). Tissues were then sectioned for further whole mount staining or imaging under a Leica TCS SP8 confocal microscope (Wetzlar, Germany). Blood vessel density was quantified by Image $\mathbf{J}(\mathrm{NIH})$. For whole mount staining, tissues were blocked with $5 \%$ goat serum in TBS containing $1 \%$ Triton $\mathrm{X}-100$ and $0.2 \%$ sodium azide for $2 \mathrm{~h}$, then incubated sequentially with primary antibodies for 4 days and secondary antibodies for 2 days.

The PDGFR $\alpha$ tracking mice were perfused with PBS and 4\% PFA after they were euthanized by $\mathrm{CO}_{2}$. Tissues were then sectioned for direct examination and imaging under a Leica TCS SP8 confocal microscope or further whole mount staining. The confocal microscope images were processed to create $3 \mathrm{D}$ videos using Fiji Imaging Processing Package [45]. The PDGFR $\alpha$ derived cells in random fields of tissue sections for each animal were counted and the average per animal was used for quantification.

Other histochemical and immunostaining of adipose tissues were conducted as previously described [46]. Briefly, adipose tissues were fixed in $4 \%$ PFA for $12 \mathrm{~h}$ at $4{ }^{\circ} \mathrm{C}$, then paraffin embedded and sectioned. Following deparaffinization, tissue sections were used for $\mathrm{H} \& \mathrm{E}$ or immunostaining. For immunostaining, sections were heated in citrate buffer for $20 \mathrm{~min}$, blocked with $5 \%$ goat serum in TBS containing $0.3 \%$ Triton $\mathrm{X}-100$ for $2 \mathrm{~h}$, then incubated sequentially with primary antibodies overnight and secondary antibodies for $1 \mathrm{~h}$. Sections were then mounted on a mounting medium (Vector Lab, Burlingame, CA, USA).

\section{Body temperature}

Rectal temperatures were measured using a TH-5 Thermalert Monitoring Thermometer (Physitemp Instruments, Inc., Clifton, NJ, USA). Body surface temperatures were measured using a FLIR E6 thermal imaging camera (FLIR System, Wilsonville, OR, USA).

\section{Real-time quantitative PCR}

qRT-PCR was performed as previously described [47]. Primers are listed in Supplementary Table S1.

\section{Serum profile analysis}

Glucose concentration was measured using a glucose meter (Bayer Contour, Tarrytown, NY, USA). Serum triglyceride was analyzed using a triglyceride colorimetric assay kit purchased from Cayman (Ann Arbor, MI, USA, cat. no. 10010303). Serum-free fatty acids level was analyzed using an EnzyChrom Free Fatty Acid Assay Kit (BioAssay Systems, Hayward, CA, USA, cat. no. 50489265).

\section{Immunoblotting analysis}

Proteins were extracted from tissue or cells using a lysis buffer ( $1 \%$ SDS, $10 \mathrm{mmol}^{-1}$ Tris- $\mathrm{HCl}, \mathrm{pH} 8.0,10 \mathrm{mmol}^{-1} \mathrm{NaCl}$, $3 \mathrm{mmol}^{-1} \quad \mathrm{MgCl}_{2}, \quad 0.5 \% \mathrm{NP}-40$, and $\left.10 \mathrm{mmoll}^{-1} \mathrm{NaF}\right)$. Western blotting was performed as previously described [47]. Protein bands were visualized by the Odyssey Infrared Imaging System (LI-COR Biosciences, Lincoln, NE, USA).

\section{Statistical analysis}

Previous experiments done were used to determine sample size with adequate statistical power. Results were analyzed using unpaired, 2-tailed Student's $t$-test or one-way ANOVA (for multiple comparison) where appropriate, using SAS 9.0 (SAS Institute Inc., Cary, NC, USA). All data were found to be normally distributed. Significance was accepted at $P<0.05$. All data are reported as mean \pm s.e.m.

\section{Conflict of Interest}

The authors declare no conflict of interest.

\section{Acknowledgements}

We thank Dr Cathy Mendelsohn for providing the R26-RAR $\alpha 403$ mice, Ann Norton in University of Idaho for assistance in FACS and Dr Dan Mullendore in Franceschi Microscopy and Imaging Center (FMIC) for assistance in using confocal microscope. The work was funded by $\mathrm{NIH}$ R01HD067449 and R21AG049976, and the National Institute of Food and Agriculture, US Department of Agriculture, under award number 2015-67015-23219. 


\section{Author contributions}

BW and MD conceived the project, designed the experiments and wrote the manuscript. BW performed the experiments. XF contributed to experiments design and assisted in teaching techniques used in this study. ZXW, XL, LZ, QT and JZ assisted with mouse experiments. NAG, SCT and JMA assisted with mouse experiments and edited the manuscript. MJZ contributed to discussion and reviewed and edited the manuscript.

\section{References}

1 Sun K, Kusminski CM, Scherer PE. Adipose tissue remodeling and obesity. J Clin Invest 2011; 121: 2094-2101.

2 Sun K, Tordjman J, Clement K et al. Fibrosis and adipose tissue dysfunction. Cell Metab 2013; 18: 470-477.

3 Rosen ED, Spiegelman BM. What we talk about when we talk about fat. Cell 2014; 156: 20-44.

4 Bartelt A, Heeren J. Adipose tissue browning and metabolic health. Nat Rev Endocrinol 2014; 10: 24-36.

5 Cao Y. Angiogenesis modulates adipogenesis and obesity. J Clin Invest 2007; 117: 2362-2368.

6 Cao YH. Angiogenesis and vascular functions in modulation of obesity, adipose metabolism, and insulin sensitivity. Cell Metab 2013; 18: 478-489.

7 Cao YH. Adipose tissue angiogenesis as a therapeutic target for obesity and metabolic diseases. Nat Rev Drug Discov 2010; 9: 107-115.

8 Rennert RC, Sorkin M, Januszyk M et al. Diabetes impairs the angiogenic potential of adipose-derived stem cells by selectively depleting cellular subpopulations. Stem Cell Res Ther 2014; 5: 79.

9 Gealekman O, Guseva N, Hartigan C et al. Depot-specific differences and insufficient subcutaneous adipose tissue angiogenesis in human obesity. Circulation 2011; 123: 186-194.

10 Sung HK, Doh KO, Son JE et al. Adipose vascular endothelial growth factor regulates metabolic homeostasis through angiogenesis. Cell Metab 2013; 17: 61-72.

11 Elias I, Franckhauser S, Ferre T et al. Adipose tissue overexpression of vascular endothelial growth factor protects against diet-induced obesity and insulin resistance. Diabetes 2012; 61: 1801-1813.

12 Sun K, Wernstedt Asterholm I, Kusminski CM et al. Dichotomous effects of VEGF-A on adipose tissue dysfunction. Proc Natl Acad Sci USA 2012; 109: 5874-5879.

13 Crisan M, Yap S, Casteilla L et al. A perivascular origin for mesenchymal stem cells in multiple human organs. Cell Stem Cell 2008; 3: 301-313.

14 Tran KV, Gealekman O, Frontini A et al. The vascular endothelium of the adipose tissue gives rise to both white and brown fat cells. Cell Metab 2012; 15: 222-229.

15 Borges J, Müller MC, Momeni A et al. In vitro analysis of the interactions between preadipocytes and endothelial cells in a 3D fibrin matrix. Minim Invasive Ther Allied Technol 2007; 16: 141-148.
16 Mercader J, Ribot J, Murano I et al. Remodeling of white adipose tissue after retinoic acid administration in mice. Endocrinology 2006; 147: 5325-5332.

17 Zhang $\mathrm{M}, \mathrm{Hu} \mathrm{P}$, Krois $\mathrm{CR}$ et al. Altered vitamin A homeostasis and increased size and adiposity in the rdh1null mouse. FASEB J 2007; 21: 2886-2896.

18 Berry DC, Noy N. All-trans-retinoic acid represses obesity and insulin resistance by activating both peroxisome proliferation-activated receptor $\beta / \delta$ and retinoic acid receptor. Mol Cell Biol 2009; 29: 3286-3296.

19 Dani C, Smith AG, Dessolin S et al. Differentiation of embryonic stem cells into adipocytes in vitro. J Cell Sci 1997; 110: 1279-1285.

20 Berry DC, DeSantis D, Soltanian H et al. Retinoic acid upregulates preadipocyte genes to block adipogenesis and suppress diet-induced obesity. Diabetes 2012; 61: 1112-1121.

21 Kumar MV, Scarpace PJ. Differential effects of retinoic acid on uncoupling protein-1 and leptin gene expression. $J$ Endocrinol 1998; 157: 237-243.

22 Puigserver P, Vazquez F, Bonet ML et al. In vitro and in vivo induction of brown adipocyte uncoupling protein (thermogenin) by retinoic acid. Biochem $J$ 1996; 317: 827-833.

23 Kogure K, Morita M, Hama S et al. Enhancement by alpha-tocopheryl hemisuccinate of nitric oxide production induced by lypopolysaccharide and interferon-gamma through the upregulation of protein kinase $\mathrm{C}$ in rat vascular smooth muscle cells. Eur J Biochem 2002; 269: 2367-2372.

24 Saito A, Sugawara A, Uruno A et al. All-trans retinoic acid induces in vitro angiogenesis via retinoic acid receptor: possible involvement of paracrine effects of endogenous vascular endothelial growth factor signaling. Endocrinology 2007; 148: 1412-1423.

25 Wang B, Fu X, Liang X et al. Maternal retinoids increase PDGFRalpha+ progenitor population and beige adipogenesis in progeny by stimulating vascular development. EBioMedicine 2017; 18: 288-299.

26 Riordan NH, Ichim TE, Min WP et al. Non-expanded adipose stromal vascular fraction cell therapy for multiple sclerosis. J Transl Med 2009; 7: 29.

27 Huch M, Koo B-K. Modeling mouse and human development using organoid cultures. Development 2015; 142: 3113-3125.

28 Sun K, Kusminski CM, Luby-Phelps $\mathrm{K}$ et al. Brown adipose tissue derived VEGF-A modulates cold tolerance and energy expenditure. Mol Metab 2014; 3: 474-483.

29 Berry R, Rodeheffer MS. Characterization of the adipocyte cellular lineage in vivo. Nat Cell Biol 2013; 15: 302-308.

30 Shao M, Hepler C, Vishvanath L et al. Fetal development of subcutaneous white adipose tissue is dependent on Zfp423. Mol Metab 2017; 6: 111-124.

31 Wang B, Wang Z, de Avila JM et al. Moderate alcohol intake induces thermogenic brown/beige adipocyte formation via elevating retinoic acid signaling. FASEB J 2017; 31. 
32 van der Heyden MA, Defize LH. Twenty one years of P19 cells: what an embryonal carcinoma cell line taught us about cardiomyocyte differentiation. Cardiovasc Res 2003; 58: 292-302.

33 Choi S-C, Choi J-H, Shim W-J et al. P19 embryonal carcinoma cells: a new model for the study of endothelial cell differentiation. Biotechnol Lett 2008; 30: 1169-1175.

34 Bruck N, Vitoux D, Ferry C et al. A coordinated phosphorylation cascade initiated by $\mathrm{p} 38 \mathrm{MAPK} / \mathrm{MSK} 1$ directs RARalpha to target promoters. EMBO J 2009; 28: 34- 47.

35 Ren M, Pozzi S, Bistulfi $G$ et al. Impaired retinoic acid (RA) signal leads to RAR $\beta 2$ epigenetic silencing and RA resistance. Mol Cell Biol 2005; 25: 10591-10603.

36 Duffy AM, Bouchier-Hayes DJ, Harmey JH. Vascular endothelial growth factor (VEGF) and its role in nonendothelial cells: autocrine signalling by VEGF. Cancer 2004, 133-144.

37 Lee YH, Petkova AP, Mottillo EP et al. In vivo identification of bipotential adipocyte progenitors recruited by beta3adrenoceptor activation and high-fat feeding. Cell Metab 2012; 15: 480-491.

38 Brakenhielm E, Cao R, Gao B et al. Angiogenesis inhibitor, TNP-470, prevents diet-induced and genetic obesity in mice. Circ Res 2004; 94: 1579-1588.

39 Rupnick MA, Panigrahy D, Zhang CY et al. Adipose tissue mass can be regulated through the vasculature. Proc Natl Acad Sci USA 2002; 99: 10730-10735.

40 Ran FA, Hsu PD, Wright $\mathrm{J}$ et al. Genome engineering using the CRISPR-Cas9 system. Nat Protoc 2013; 8: 2281-2308.

41 Wang B, Fu X, Zhu M-J et al. Retinoic acid inhibits white adipogenesis by disrupting GADD45A-mediated Zfp423 DNA demethylation. J Mol Cell Biol 2017; 9: 338-349.
42 Rosselot C, Spraggon L, Chia I et al. Non-cell-autonomous retinoid signaling is crucial for renal development. Development 2010; 137: 283-292.

43 Khan A, Ashrafpour H, Huang N et al. Acute local subcutaneous VEGF165 injection for augmentation of skin flap viability: efficacy and mechanism. Am J Physiol Regul Integr Comp Physiol 2004; 287: R1219-R1229.

44 Li YW, Song Y, Zhao L et al. Direct labeling and visualization of blood vessels with lipophilic carbocyanine dye DiI. Nat Protoc 2008; 3: 1703-1708.

45 Schindelin J, Arganda-Carreras I, Frise E et al. Fiji: an open-source platform for biological-image analysis. Nat Methods 2012; 9: 676-682.

$46 \mathrm{Fu} \mathrm{X}$, Zhu M, Zhang S et al. Obesity impairs skeletal muscle regeneration via inhibition of AMP-activated protein kinase. Diabetes 2015; 65: 188-200.

47 Wang B, Yang G, Liang X et al. Grape seed extract prevents skeletal muscle wasting in interleukin 10 knockout mice. BMC Complement Altern Med 2014; 14: 162.

(Supplementary information is linked to the online version of the paper on the Cell Discovery website.)

(c) (i) This work is licensed under a Creative Commons Attribution 4.0 International License. The images or other third party material in this article are included in the article's Creative Commons license, unless indicated otherwise in the credit line; if the material is not included under the Creative Commons license, users will need to obtain permission from the license holder to reproduce the material. To view a copy of this license, visit http://creativecommons.org/licenses/by/4.0/

(C) The Author(s) 2017 